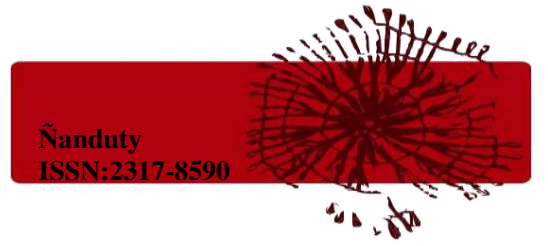

\title{
Alguma Introdução: Multiplicando o Cosmos, Dividindo a Política
}

Pedro Alex Rodrigues Viana (IFCS/UFRJ)

Leif Grünewald (PPGAnt/UFGD)

Este dossiê versa sobre a noção de 'cosmopolítica', criada pela filósofa Isabelle Stengers, pela qual se compreenderia que uma 'política' não pode figurar desassociada de uma noção de 'natureza', de uma multiplicidade de mundos divergentes que se articulam e diferem uns dos outros - sugestão que entrou na pauta de interesses da Etnologia Indígena contemporânea pelas mãos de Renato Sztutman (2005). O interesse principal desse dossiê é, portanto, oferecer ao leitor ou a leitora artigos de jovens pesquisadores que utilizam esse conceito - de forma implícita ou explicita - nas suas pesquisas (em coletivos ameríndios, mas em outros também), constituído na forma de uma cartografia das relações mobilizadas pelo pensamento em relação com formas humanas e/ou não-humanas de alteridade em contextos diversos.

Cabe agora questionar, portanto, por que cosmopolítica? Se o emprego do conceito de cosmopolítica entrou na pauta da etnologia indígena contemporânea pelas mãos de Renato Sztutman (2005) em sua constatação - inspirada certamente nas intervenções de Bruno Latour e de Isabelle Stengers - de que dificilmente se poderia desarticular a noção de 'política' da noção de 'natureza' e, nesse sentido, seria impossível desassociar uma política 'intrahumana' de uma política 'extrahumana' - o que implicaria repensar, então, todo o projeto de uma antropologia política que integrasse aos coletivos humanos toda uma dimensão não-humana, é sem dúvida legítimo afirmar, por outro lado, a existência de uma dimensão suplementar do conceito de cosmopolítica - cuja base também é a discussão de Latour - em que reconhecer-se-ia que sendo verdade o perigo do fechamento prematuro do 'cósmico' ou do 'político' sobre si mesmos, a função do 'cósmico' em uma cosmopolítica seria impedir o fechamento prematuro do 'político', assim como o papel atribuído ao 'político' seria o de barrar que 'cósmico' feche-se sobre si mesmo.

Ora, e se a imagem mobilizada por Sztutman quando fez ressoar o conceito de cosmopolítica com a etnografia amazônica atual parece ter sido, sobretudo, a do englobamento do 'político' pelo 'cósmico', a idéia de um domínio cósmico que permita a penetração da natureza no político e a de um político que impeça a natureza 


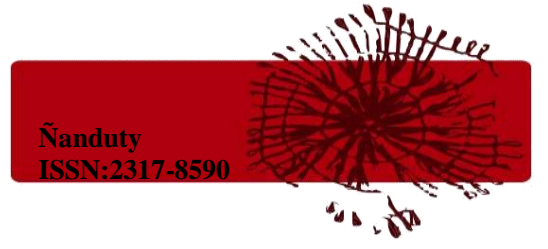

de 'naturalizar' o político (Latour, 2004a: 4) parece trazer-nos um desafio outro que é: como recompor em um conceito os traços do desenho de uma topologia em que o 'político' deve ser imanente ao 'cósmico' e vice-versa, de modo que qualquer ponto escolhido no 'político', por exemplo, já abrigue em seu interior um foco possível do 'cósmico', assim como qualquer ponto no âmbito do 'cósmico' já seja um uma espécie de limite (no sentido matemático do termo) entre este e o 'político'?

Parece-nos, diante de uma questão como essa, que o caso de uma investigação sobre o conceito de cosmopolítica e os movimentos que haveriam de existir em seu interior pode contribuir ainda para a compreensão de um ponto importante, que diz respeito à irredutibilidade desse conceito a uma questão de hierarquia ou de totalidade (cf. Viveiros de Castro, 2002) na qual a noção de cosmopolítica quando feita ressoar com os materiais amazônicos, mas não só eles, revelar-se-ia apenas uma forma de ação política na qual o 'cósmico' engloba (e subordina) o 'político', transformando-o nesse movimento somente em um 'político' mais amplo.

O que gostariamos de sugerir através dessa distorção e dessa deformação do conceito de cosmopolítica é uma vontade de crença de que um conceito como este não possa suprimir antecipadamente toda ênfase posta pela etnologia amazônica, sobre a qual interveio Viveiros de Castro (2002: 429) - e que pode ser expandida para pensar outros coletivos humanos -, e cujo argumento remontamos parcialmente aqui - no papel constitutivo da alteridade, dando contornos a um regime em que o englobamento não produz uma unidade metafísica superior, pois, como destacaria ainda o autor, "não existe identidade transcendente entre diferença e identidade apenas diferença de cima a baixo" (Viveiros de Castro, ibidem).

Uma hipótese fundamental que deu origem a nos aprofundarmos em nossos respectivos projetos de pesquisas e que inspirou a organização desse dossiê é a de que há uma circulação e uma oscilação fundamental entre os domínios cósmico e político. Se as intervenções de Latour e de Sztutman sobre os usos do conceito, e a lição que nos ensina Viveiros de Castro (1986:32) em sua monografia sobre os Araweté de que há "formas diferenciais de lidar com o fato da diferença", não gostaríamos de esconder a inspiração advinda dos trabalhos de Nelms (2007) e a hipótese instigante que norteia o pensamento do autor a respeito do conceito de relação social, e o artigo de Corsín-Jimenez e Willerslev (2008) sobre a noção de reversibilidade.

Em poucas palavras, a sugestão posta no trabalho de 2007 é a de que uma prática nunca é somente idêntica a si mesma. Ela sempre carrega consigo, ao 


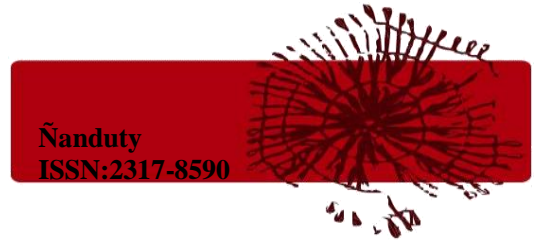

contrário, um virtual, uma 'sombra' invisível, que se atualiza e toma o lugar que ocupava antes. Ora, lendo-o a luz do trabalho de Bruno Latour (idem) onde a hipótese de que a presença do 'cósmico' na cosmopolítica impede o fechamento prematuro do ‘político' e vice-versa, e do trabalho de Nelms - onde a hipótese de que o social e o relacional orbitam um ao redor do outro, articulando nesse movimento de 'translação' o perímetro de um com o perímetro do outro, a interrogação que parecia acrescer-se ao trabalho de Sztutman, por exemplo, era a de como fazer ressoar com o conceito de cosmopolítica a ideia de uma circulação (ou de uma perseguição mútua, talvez) para as noções de política e de cosmologia tal como mobilizadas em diferentes sociocosmologias.

Teríamos ainda outro ponto importante que poderia contribuir para um estudo sobre o conceito de cosmopolítica que remete tanto ao trabalho de Wagner (1976) quanto à intuição e ao tratamento de Lévi-Strauss (1991) do 'dualismo em desequilíbrio perpétuo'. No intuito de tornar mais econômica a apresentação de um esboço sobre este ponto em particular, gostaria de oferecer agora um par de breve caracterizações etnográficas sobre o tema retirado da tese de Sztutman (2005).

A primeira delas diz respeito à caracterização que o autor nos oferece, através da comparação de diferentes materiais bibliográficos sobre os antigos Tupi da costa, de um conselho de Anciãos tupinambá: instância decisória composta por chefes de maloca, grandes guerreiros e pajés, lugar de fala, fumo e cauim. Espaço, verdadeiramente, de dupla comunicação, pois se haveria ali o diálogo entre alguns homens tupinambá, haveria também o diálogo destes com o mundo sobrenatural, donde se reconheceria a impossibilidade de fazer purificar em um espaço como este um coletivo plenamente humano.

Por outro lado, podemos encontrar um problema similar a partir do retorno à descrição etnográfica realizada por Carlos Fausto sobre os Parakanã Ocidentais e em um comentário sobre a guerra como mobilizada pelos homens desse povo que esta resulta, como chamou o autor, em "vertigem centrífuga": um movimento constante de desarticulação daquilo que poderia ser tido como uma interioridade, um espaço público plenamente humano.

Assim sendo, o autor concluiria, de maneira análoga ao que faria ainda para o caso do conselho de anciãos tupinambá que mencionei anteriormente, que a predação (que nunca figura desassociada de uma ética...) também implica num englobamento da política pelo cosmos. E eis, então, a questão que se põe Sztutman: qual é, assim, o 


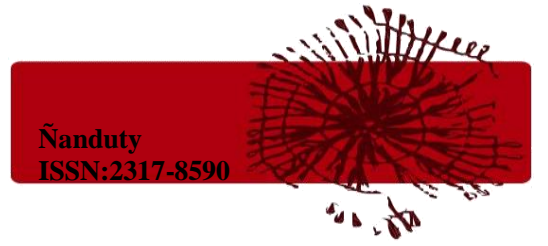

'limite' da predação? Justamente a domesticação/familiarização (que se oporia a predação) que abriria à constituição de identidades, grupos e pessoas. Pois bem. Se as duas passagens retiradas sobre um uso do conceito de cosmopolítica retiradas da brilhante tese de Sztutman são, sobretudo, esclarecedoras sobre os eclipsamentos a que estão sujeitos o cósmico e a política em diferentes contextos nas sociocosmologias indígenas, penso que ambas são igualmente intrigantes e levam-nos a interrogar ainda o seguinte: considerando-se a assimetria entre o cosmos e a política e os eclipsamentos a que os dois termos estão sujeitos, que espécie de dinâmica de 'encaixamentos' (ou de desdobramentos) haveriam de existir entre eles? Seria incorreto sugerir que no interior de um dos pólos desse conceito sempre se desdobra os termos da oposição inicial entre o cosmos e a política?

Não esperamos termos alcançados essas respostas, mas sim através dos vários artigos que compõe esse dossiê devolver uma imagem de como coletivos, ameríndios e outros, produzem seu mundo. Nesses mundos, as relações são sempre atravessadas por entes e potências não-humanas, invisíveis. Oposições clássicas - visível/invisível, natureza/cultura, crença/razão, indivíduo/sociedade, humano/não-humano - que ainda são heuristicamente necessárias, aparecem nesses trabalhos como instáveis, não substanciais e sempre relacionais. Portanto, não é mais possível a certeza de um cosmo (ou natureza) único, onde vários coletivos humanos (ou culturas) habitam. Mas sim uma multiplicidade de mundos, que se diferem, interagem, se transformam e, assim, fazem a vida acontecer. Essas relações de conflito e aliança sociocosmológicos, exigem desses coletivos uma cosmo/política. Segue uma breve apresentação do que se encontrará nesse dossiê.

O trabalho de Silveira traz uma contribuição importante para a relação da cosmopolítica pensada dentro da experiência da possessão. As relações entre humanos e não-humanos (neste caso, os espíritos que são incorporados) são determinantes para compreender a possessão para além de uma explicação unicamente centrada no indivíduo. Utilizando a teoria de Latour do ator-rede (2012) e na esteira das análises de Marcio Goldman, o terreiro aparece como um espaço político, de negociação entre humanos e não-humanos, que se influenciam mutuamente. A proposta de um exercício ontológico utilizando a teoria de Latour, proporciona a Silveira uma ferramenta analítica importante para demonstrar como a experiência da possessão é uma negociação cosmopolítica, com atores humanos e não-humanos, que só pode ser 


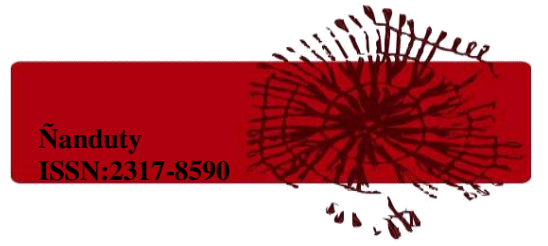

apreendida nos seus sistemas de relações e conexões, e não em explicações individualistas e substanciais.

O texto de Evandro Bonfim nos apresenta uma abordagem interessante entre linguística e antropologia. Falando sobre o povo Bakairi (grupo falante de uma língua Karib, Centro-Oeste do Brasil), o autor nos demonstra em uma abordagem focada nos componentes semânticos funcionais do léxico dessa língua, que as relações de aliança e conflito com entes e potência de outras categorias ontológicas, tão cara ao pensamento dos ameríndios, aparecem com marcas diferenciantes que remete ao mito, ao rito e a cosmologia desse povo. Através de uma análise dessas marcas, ele propõe que é possível falar sobre uma "gramatica cosmopolítica" da língua Bakairi, abrindo uma via pioneira para aprofundarmos as análises sobre política e cosmologia, na linguística e na antropologia.

O texto de Silva-Bueno, sobre o povo Ticuna (língua isolada, Alto Solimões), discorre sobre o problema da transformação e metamorfose na cosmologia desse povo. Seguindo a via dos mitos e de uma complexa rede de relações sociopolíticas, a autora nos conta como esse povo utiliza categoria ngo'o (seres nefastos, traduzidos para português como bichos ou vampiros), presente nas histórias do "tempo dos antigos", para pensar os rumores sobre "feiticeiros"/usuários do livro de São Cipriano e as mortes por enforcamento nos dias de hoje, que os Ticuna acreditam ser pessoas que se metamorfosearam nesses seres.

O texto de Pereira, sobre os Mbya Guarani (que viviam em Niterói e agora em Maricá, Rio de Janeiro), nos apresenta um rico contexto etnográfico de uma aldeia urbana e a relação desse povo com os brancos (jurua) que ora podem resvalar no conflito, ora na familiarização e, até mesmo, em casamentos. Essas relações são sempre mediadas pelas categorias cosmológicas que esse povo tem para pensar e organizar seu mundo ao lado do mundo dos brancos.

O texto de Viana, sobre os asháninka (povo falante de uma língua da família aruaque que vivem no vale do Ene, Selva Central, Peru) busca compreender a razão pela qual as acusações de feitiçaria entre-si se potencializaram e o surgimento da figura de gringos superpoderosos preparados para acabar definitivamente com os indígenas no repertório cosmológico desse povo, num contexto de violência e projetos de desenvolvimento estimulados pelo governo peruano. A cosmopolítica é o meio pelo qual, segundo o autor, esse grupo mantem sua resiliência no seu mundo vivido. 


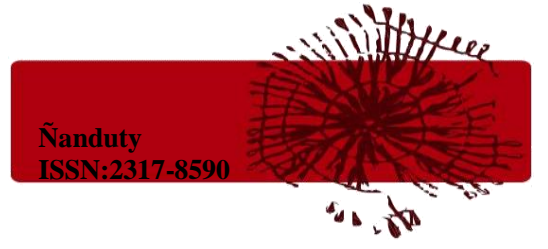

O trabalho de Benites e Grünewald, fruto de um bom encontro entre um aluno indígena (Guarani-Kaiowá) e seu professor, nos traz uma bela reflexão, em duas vozes, sobre aquilo que consideramos a arte do fazer antropológico, a saber: dar toda a potencia e criatividade do pensamento do outro para a produção de conceitos; conceitos esses que não podem ser reduzidos aos conceitos ocidentais, nem uma representação do pensamento ameríndio - mas conceitos entre-dois, oriundos da afetação de modos de pensamento, emergidos da interação entre dois mundos. Assim, Benites, o aluno Guarani-Kaiowá, pensando com o tata jara (dono do fogo) nos propõe uma "antropologia simétrica/assimétrica cruzada" que seria o movimento que garante a existência dessa sociedade e, ao mesmo tempo, uma forma dele se comunicar com a nossa antropologia.

No trabalho de Christopher Hewlett, sobre os Amawaka (povo de língua pano, que habitam o rio Inuya, leste do Peru), busca compreender o processo de mudança que esse coletivo indígena passou nos últimos anos para se tornarem 'cidadãos peruanos'. Os Amawaka eram um povo que vivia em pequenos grupos dispersos pelo território, mas hoje vivem numa "comunidade nativa", próximos uns dos outros, tendo que se engajar em novas formas de socialidade - que emergiram através da relação com o estado peruano - para construir o seu "mundo vivido".

O trabalho de Maria Acselrad, sobre os caboclinhos (Goiana, Pernambuco) traz uma contribuição sobre as relações entre invisível e o visível no universo das danças populares brasileiras. Para além de uma análise coreográfica centrada no corpo, esse texto traz à baila as relações de guerra - e de "que tipo de guerra?" como se questiona a autora - dentro de contextos de socialidade dos grupos que dançam caboclinho. Explorando a hipótese de Clastres para além do universo ameríndio, Acselrad nos demonstra como "muitas coisas acontecem enquanto se dança".

A seção destinada à entrevista abre alas para dois ensaios de produções audiovisuais.

O de Iulik Lomba Farias lança luz sobre uma questão importante. Sob uma perspectiva Guarani, o texto do autor objetiva nos oferecer um conjunto de reflexões sobre a questão da forma e conteúdo tal como apresentadas em dois filmes realizados pelo projeto Vídeo nas Aldeias: "Tava - A casa de pedra (2012)" e "Bicicletas de Nhanderu (2011)". Quem tiver curiosidade de lê-lo, encontrará meditações sobre relações cosmopolíticas disparadas pelas imagens e as formas fílmicas com as quais o sistema intelectual Guarani opera. 
O ensaio de Catia Paranhos Martins suscita valiosas inquietações sobre o documentário "Ilegal - A vida não espera" (2014). Se na película a discussão, a priori, foca em solos brasileiros os usos medicinais da maconha, a perspectiva e/ou abordagem toca outras dimensões éticas e políticas desse debate sobre a legalização da cannabis. Ilegal x legal; Big Farma x doenças negligenciadas (de pessoas e países pobres) e "O cuidado - ainda - feminino" x ciência masculina. Dualidades que não cabem em si porque a saúde é política, e a vida não espera. "Ela escapa, insiste em se reinventar e resiste ao jogo de interesses biopolíticos".

Por fim, a resenha de Marcilio Lucas sobre o livro Marx Selvagem de Jean Tible (2013), vem compor o quadro que esse dossiê propôs de aproximar o pensamento ocidental dos pensadores "menores" e seus discursos cosmopolíticos e nos devolve uma imagem de Marx capaz de dialogar com esses outros povos.

Desejosos que se deleitem. 